\title{
Multi-Criteria Decision Analysis Methods in the Mobile Cloud Offloading Paradigm
}

\author{
Hind Bangui 1,2,3,* (1) , Mouzhi Ge ${ }^{1,2}$, Barbora Buhnova ${ }^{1,2}$, Said Rakrak ${ }^{3}$, Said Raghay ${ }^{3}$ \\ and Tomas Pitner ${ }^{1,2}$ (iD \\ 1 Institute of Computer Science, Masaryk University, 60200 Brno, Czech Republic; \\ mouzhi.ge@muni.cz (M.G.); buhnova@fi.muni.cz (B.B.); tomp@fi.muni.cz (T.P.) \\ 2 Faculty of Informatics, Masaryk University, 60200 Brno, Czech Republic \\ 3 Applied Mathematics and Computer Science Laboratory, Cadi Ayyad University, \\ Marrakech 40000, Morocco; s.rakrak@uca.ma (S.R.); s.raghay@uca.ma (S.R.) \\ * Correspondence: hind.bangui@mail.muni.cz
}

Received: 18 October 2017; Accepted: 10 November 2017; Published: 13 November 2017

\begin{abstract}
Mobile cloud computing (MCC) is becoming a popular mobile technology that aims to augment local resources of mobile devices, such as energy, computing, and storage, by using available cloud services and functionalities. The offloading process is one of the techniques used in MCC to enhance the capabilities of mobile devices by moving mobile data and computation-intensive operations to cloud platforms. Several techniques have been proposed to perform and improve the efficiency and effectiveness of the offloading process, such as multi-criteria decision analysis (MCDA). MCDA is a well-known concept that aims to select the best solution among several alternatives by evaluating multiple conflicting criteria, explicitly in decision making. However, as there are a variety of platforms and technologies in mobile cloud computing, it is still challenging for the offloading process to reach a satisfactory quality of service from the perspective of customers' computational service requests. Thus, in this paper, we conduct a literature review that leads to a better understanding of the usability of the MCDA methods in the offloading operation that is strongly reliant on the mobile environment, network operators, and cloud services. Furthermore, we discuss the challenges and opportunities of these MCDA techniques for offloading research in mobile cloud computing. Finally, we recommend a set of future research directions in MCDA used for the mobile cloud offloading process.
\end{abstract}

Keywords: mobile cloud computing; offloading; mobile computing; cloud computing; network; MCDA; decision; criteria

\section{Introduction}

Mobile cloud computing (MCC) is one of the critical instances in cloud-based systems and key innovations in Internet of Things (IoT) networks [1] where mobile devices exploit external cloud resources to augment their computational capabilities, e.g., storage space, and optimize their local services [2-4]. As cloud computing offers powerful and unlimited resources for use when needed at a low cost, mobile devices exploit the distributed computing paradigm to obtain a better user experience and high performance by using cloud services anytime and anywhere. Moreover, it is an advancement of several technologies like grid computing, distributed computing, and parallel computing $[5,6]$. Taking into account the advantages of MCC, the mobile users can remotely connect to the cloud server and achieve an optimal computational power compared to executing everything locally $[7,8]$.

The offloading process is one of the techniques used in MCC to augment and optimize the computational capabilities of mobile devices [9]. This technique consists of partitioning and analyzing the entire mobile application. Then, the most resource-intensive components of this application 
are identified and offloaded remotely to the selected powerful cloud server. This later performs the requested computation and returns the results to the end mobile client [10]. As a result, the requirement of mobile devices with a high computing capability and resources are reduced. One typical example of an offloaded mobile application is mobile healthcare (m-healthcare) [11-14], which utilizes a strong wireless sensor network (WSN) to monitor the current health of the patient. The main steps for the execution of an $\mathrm{m}$-healthcare application are as follows: Generate large amounts of healthcare data which consumes resources of the mobile device, offload the application onto a cloud server, and send the result back to the mobile patient. In this case, the m-healthcare application exploits the advantages of a cloud environment to make precise and real-time decisions. By sharing personal health information among healthcare cloud providers, the mobile cloud applications can efficiently empower and facilitate patient treatment for medical consultation. Consequently, the mobile patient can reduce the cost and overcome the limitations of traditional medical treatment, such as medical errors and computation speed limits.

The migration of heavy computation from mobile devices to remote cloud servers through communication networks could be seen as a straightforward process. However, the diversity in MCC affects the consumption of mobile cloud services in real time since the selection process of cloud services depends on the available multiple services which belong to heterogeneous environments in the MCC paradigm.

Let us take a network as an example to show one of the existing diversity aspects in MCC. It is clear that mobile cloud offloading essentially depends on the network technologies [15-17]. Consequently, for each offloading operation, a sophisticated network medium among the available network services is selected to support the offloading process by providing high bandwidth connections. However, most of the current research work has only given limited consideration to the selection of network services, such as [18] that has presented an online energy-aware resource provisioning scheduler for TCP/IP-based mobile cloud applications. Also, in [19], only a TCP/IP mobile connection has been considered. Another example is [20], where LTE and WiFi technologies have only been used for the transmission of computing tasks from wearable devices and smartphones in the cloud infrastructure. Indeed, the mobile clients could be surrounded by multiple network connections ( $\mathrm{Wi}-\mathrm{Fi}, 4 \mathrm{G}$, etc.) that are available at the same time to provide similar services to them while on the move. In this case, the clients deal with diversity in the network environment and have to choose one of the network candidates to process their requests externally.

To deal with the variations in MCC, multi-criteria decision analysis (MCDA) methods are applied [21-23]. The main goal of MCDA methods is to solve complex problems by selecting, comparing, and ranking different attributes of multiple alternatives in a flexible manner. This means that the MCDA techniques handle the diversity in MCC by managing different information from various environments, considering many factors that affect the selection process and deciding which service is the most suitable one for the end-user when making the final decision.

In this work, we conduct a review of MCDA methods in an offloading operation. Compared to the existing reviews that focus on the implementation of MCDA in cloud service selection [21,24], this is to the best of our knowledge the first work that addresses the exploitation of MCDA in the mobile cloud offloading paradigm. Thus, the basic objective of this comprehensive literature review is to highlight the exploitation of MCDA methods in the mobile cloud offloading process. The contributions of this study can be summarized as follows:

(1) Based on our literature review, we focus on identifying the MCDA methods most widely used in cloud offloading by selecting specific approaches in mobile cloud offloading that clearly utilize MCDA methods.

(2) For each selected approach, we focus on describing the primary goal of the used MCDA methods and extracting keywords related to the addressed MCDA problems. 
(3) To better understand how MCDA methods deal with the diversity in the offloading process, we classify the extracted keywords in three main environments which are: clouds, mobile environment, and networks.

(4) Finally, we discuss major findings, identify the key challenges in the current mobile cloud offloading process based on MCDA methods, and define the research roadmap for better implementation and optimization of MCDA methods in the mobile cloud offloading paradigm.

The remainder of the paper is structured as follows. Section 2 describes the concept of offloading in the MCC. Section 3 provides a review of the MCDA concept. Then, Section 4 carries out a literature review on MCDA methods applied to the mobile cloud offloading paradigm. Next, Section 5 focuses on the discussion of the major findings, challenges, and opportunities. Finally, Section 6 concludes the work and outlines future research.

\section{Overview of the Offloading Process}

Because of cloud-based computation offloading, mobile devices can extend cloud computing services to mobile applications by offering virtually unlimited and dynamic resources of computation (Figure 1). Thus, the small screen devices can reduce battery power consumption, and execute applications that they are otherwise unable to execute due to the constrained resources (i.e., limited computation power, memory, storage, and energy). Currently, many mobile cloud applications involve intensive communication that consumes a significant part of the overall energy, such as m-healthcare, m-learning, social networks, and gaming, among others. Thus, the primary objective of offloading is to enhance the performance of mobile devices by utilizing cloud resources.

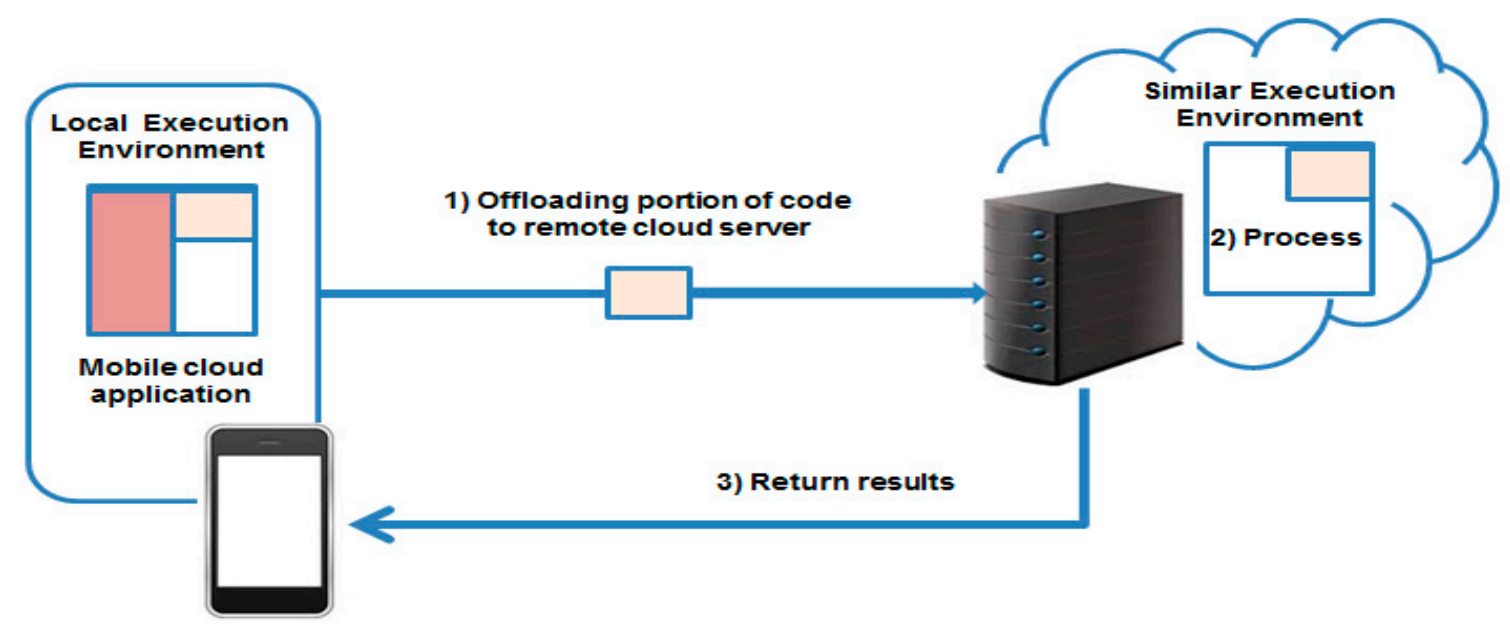

Figure 1. Offloading process.

The cloud-based computation offloading process can be described as follows: Firstly, the program needs to be partitioned. Next, the offloading decision chooses a specific execution point of the mobile application that consumes a significant part of the local energy, and decides to offload a portion of the application to the cloud where the computation is performed in less time compared to the local execution of the mobile device. Upon receiving the migration request, an offloading system requires a similar execution environment as the mobile client. As a result, one server for each mobile device creates a dedicated virtual machine (VM) for the device, loads the executable application, and starts the execution. Until the results return from the cloud provider, the mobile device continues to run other threads or go into a low power sleep state. Finally, the offloaded portion returns to the mobile application, and merges back to the original process. Accordingly, cloud based computation offloading can save energy and extend the battery life of mobile devices. 
On the other hand, the idea of offloading computation-intensive tasks to the surrounding servers, clusters, or grids is not new. All are attempts to save energy without degrading the normal response time of the mobile applications and represent less computational effort for the mobile devices. Cloud computing, which focuses on XaaS (X-as-a-Service) offered in a pay-as-you-go manner, is another advanced offloading technique that can strongly facilitate computation and assume the availability of unlimited resources anytime and anywhere. Additionally, the virtualization of servers in cloud computing presents the major difference between cloud computing and the other existing solutions, and it attains high utilization by allowing one server to compute several tasks at the same time. Therefore, multi-tenancy is the most important concept for cloud computing. Thus, offloading to cloud is one of the best available solutions for extending the battery life of mobile devices. Further, the effectiveness of an offloading system is determined by its ability to reply to the four fundamental questions which are:

- What to offload: Before offloading, the program needs to be partitioned by using static annotations (or manual partitioning), an automated mechanism, or at runtime. Then, the offloading decision decides what portion of code should be offloaded.

- When to offload: Different parameters influence the offloading decisions that look for less computational effort for the mobile device, such as available bandwidth, data size to transmit, and energy. Conceptually, the offloading process should take place when the mobile client cannot save energy to execute the code and improve the performance of the mobile application. In contrast, the code should be executed locally when the mobile client has enough resources to execute the entire code. As a result, a mobile client can reduce the time that is consumed in transmission of the job to the cloud and avoid the network overload.

- Where to offload: It defines the selected server (or a cloud provider in case cloud based computation) in which the code has to be offloaded.

- How to offload: It introduces an offloading strategy that describes how the device should schedule code offloading operations.

\section{Overview of MCDA Methods}

The offloading process contains several stages (see Table 1) before starting to offload the mobile tasks to the selected cloud service candidate. Due to the nature of MCC, the offloading process is a source of multiple criteria that originate from the presence of different environments [25]. Thus, the selection of the best service candidate among several available services is a crucial task in MCC.

Table 1. Offloading process strategy.

\begin{tabular}{|c|c|}
\hline Fundamental Questions of Offloading Process & Description \\
\hline What to offload? & $\begin{array}{l}\text { Before offloading, the program needs to be partitioned: } \\
\text { - } \quad \text { Manually by the programmer. } \\
\text { - } \quad \text { Automatically by the compiler. } \\
\text { - } \quad \text { At runtime. }\end{array}$ \\
\hline $\begin{array}{l}\text { When to offload? } \\
\text { (Objective) }\end{array}$ & $\begin{array}{ll}\text { - } & \text { Reducing time of execution. } \\
\text { - } & \text { Saving energy. } \\
\text { - } & \text { Improving performance. } \\
\text { - } & \text { Reducing network overhead. }\end{array}$ \\
\hline How to offload? & - Using virtualization technology. \\
\hline Where to offload? & $\begin{array}{l}\text { - Cloud computing, cloudlet, mobile cloudlet, mobile } \\
\text { devices as ad hoc cloud. }\end{array}$ \\
\hline
\end{tabular}

Due to the presence of more than one criterion in the mobile cloud offloading paradigm, the multi-criteria decision analysis (MCDA), called also multiple criteria decision making (MCDM), is required. MCDA is a sub-discipline of operations research that aims at selecting the best solution, 
called alternative, among several choices by explicitly evaluating multiple conflicting criteria in decision making. Furthermore, the evaluation is done by a single decision maker or by a single group of decision makers [26-28].

There are five fundamental steps that each MCDA method follows to solve an MCDA problem. Firstly, the consistent family of relevant criteria is determined to construct the basis on which the alternatives are ordered or selected. Next, a set of feasible alternatives is considered. These alternatives represent the preferred solutions set from which the decision-maker should select the best alternative. Then, every alternative is scored with respect to specific criteria to construct a matrix or table that is named the evaluation matrix, decision matrix, payoff matrix, performance table, or evaluation table. Next, the weights are defined to determine the relative importance of the different criteria used in the decision problem. The last step consists of finding the best alternative among a set of feasible alternatives by transforming the evaluation matrix into a score using approaches that are specific to the different MCDA methods, such as AHP and TOPSIS. According to the literature, there are a large number of MCDA methods available $[26,29,30]$. Table 2 presents a summary of some of the most popular examples of them.

Table 2. Summary of different MCDA techniques and capabilities.

\begin{tabular}{|c|c|c|}
\hline Name & Abbreviations & Objective \\
\hline AHP [31] & Analytic Hierarchy Process & $\begin{array}{l}\text { Pairwise comparison of attributes structured into a } \\
\text { hierarchal relationship, where qualitative and } \\
\text { quantitative criteria are used to evaluate alternatives. }\end{array}$ \\
\hline PROMETHEE [32] & $\begin{array}{l}\text { Preference Ranking Organization } \\
\text { Method of Enrichment Evaluations }\end{array}$ & $\begin{array}{l}\text { Pairwise comparison between the alternatives used to } \\
\text { determine and eliminate alternatives dominated by } \\
\text { other alternatives. }\end{array}$ \\
\hline TOPSIS [33] & $\begin{array}{l}\text { Technique for Order of Preference } \\
\text { by Similarity to Ideal Solution }\end{array}$ & $\begin{array}{l}\text { Selection of an alternative simultaneously the closest to } \\
\text { the positive-solution and the farthest from the } \\
\text { negative-ideal solution. }\end{array}$ \\
\hline GRA [34] & Grey Relational Analysis & $\begin{array}{l}\text { Solution of problems with complicated } \\
\text { interrelationships between factors and variables. }\end{array}$ \\
\hline ELECTRE [35] & $\begin{array}{l}\text { ELimination and Choice } \\
\text { Expresing REality }\end{array}$ & $\begin{array}{l}\text { Pairwise comparison between the alternatives used to } \\
\text { determine and eliminate alternatives dominated by } \\
\text { other alternatives. Similar to PROMETHEE but } \\
\text { differing in the pairwise comparison stage. }\end{array}$ \\
\hline ANP [31] & Analytic Network Process & $\begin{array}{l}\text { Extension of AHP. More general representation of } \\
\text { interrelationships among decision levels and attributes. }\end{array}$ \\
\hline VIKOR [36] & $\begin{array}{l}\text { ViseKriterijumska Optimizacija I } \\
\text { Kompromisno Resenje }\end{array}$ & $\begin{array}{l}\text { VIKOR based on AHP. Ranking of compromises } \\
\text { representing indices derived from a measure of } \\
\text { "closeness" to the "ideal" solution. In contrast to the } \\
\text { basic principle of the TOPSIS method is that the } \\
\text { selected alternative should have the "shortest distance" } \\
\text { from the ideal solution and the "farthest distance" from } \\
\text { the "anti-ideal" solution. }\end{array}$ \\
\hline MAVT [37] & Multi-Attribute Value Theory & $\begin{array}{l}\text { Overall priority values of alternatives are calculated } \\
\text { based on the objectives' weights, performance scores of } \\
\text { alternatives and value-functions. }\end{array}$ \\
\hline MAUT [38] & Multi-Attribute Utility Theory & $\begin{array}{l}\text { Extension of MAVT, includes probabilities and risk } \\
\text { attitudes that are used to form utility functions }\end{array}$ \\
\hline
\end{tabular}

To ensure the reliability and availability of selected services, the MCDA methods have motivated research in several areas. In the literature, AHP and TOPSIS have been widely used in solving many complicated decision-making problems in several domains [29,39-44]. According to the Web of Science platform [45], the total publications for the AHP and TOPSIS method are 9362 and 3025 (Figure 2), respectively, from Web of Science Core Collection between 2010 and 2016. Moreover, based on the Web of Science database [45], the classification of AHP and TOPSIS publications ranked by research areas mostly results in engineering and computer science areas. Therefore, the MCDA methods have 
covered a lot of ground to enhance the evaluation process as well as guarantee the sustainability of systems, which is an important factor for the growth of an industrial or research domain. Thus, in the next section, we review how the benefits of MCDA methods are investigated in the mobile cloud paradigm to support the offloading operation.

\section{Total publications 3025}
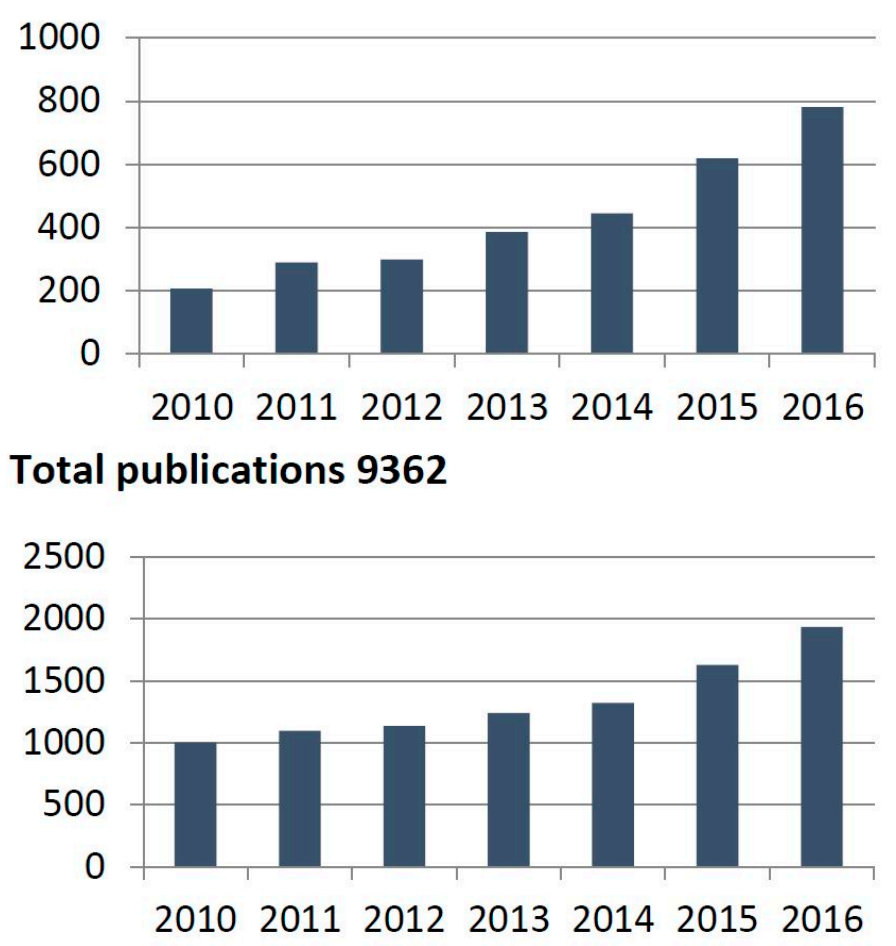

Figure 2. Total publications of AHP and TOPSIS methods between 2010 and 2016 (Source: Web of Science platform).

\section{MCDA in the Offloading Process}

The description of the offloading process in MCC can be seen as a simple operation that aims to enhance the capabilities of small mobile devices by using powerful computing nodes remotely. However, there are many factors that influence the decision making process for task migration in MCC [46], such as cost, mobile user preferences, latency, cloud characteristics, and others. Moreover, these factors could be irregular, because the MCC paradigm is built based on three heterogeneous and unstable environments [25], which are: mobile environment, different cloud platforms [47], and various network communications.

We identified two ways $[48,49]$ to consume cloud services in the mobile cloud environment which are as follows: task delegation where the mobile application acts as a traditional cloud client that invokes cloud services directly and an offloading operation where a mobile application is partitioned and analyzed. Then, the most computationally expensive operations at code level could be migrated to a selected cloud platform. Maybe the two approaches have the same three environments; however, in the case of the delegation, the mobile devices can consume cloud services without participating in the process. Thus, the offloading mobile components to the cloud are considered a complex operation that is difficult to control in a mobile cloud infrastructure, due to the dynamic nature and many real-time constraints of the overall offloading system.

Therefore, in this paper, we aim to draw together a number of papers which address the offloading process based on MCDA methods in the area of mobile cloud computing. We also classify the utilization 
of MCDA methods in offloading by using two keywords which are: Certainty that describes MCDA methods using determined values of criteria to solve an MCDA issue, and uncertainty that describes the MCDA methods dealing with imprecise systems. Furthermore, we specify the exact environment from which the criteria are extracted to solve an MCDA problem.

The mobile cloud offloading papers used for this purpose were selected by searching academic databases and well-known publishers such as Sciencedirect, Google Scholar, ACM Digital Library, IEEE Xplore Digital Library, and Springer, as well as a general Google search. Furthermore, we used general and specific keywords characterizing the mobile cloud offloading process based on MCDA methods, such as offloading, decision making, rank, mobile applications, partitioning, allocation, Wi-Fi, preference, alternatives, criteria, certain, uncertain, and so on. We limited the search to up-to-date papers from the last five years, which covers the period from 2013 to 2017. After collecting the search results, each paper underwent a relevance check, during which its relevance to both MCDA methods and the mobile cloud offloading paradigm was verified.

\section{Discussion}

In this section, we focus on the analysis and classification of the MCDA methods that are applied in the mobile cloud environment, and discuss challenges that may prevent the advancement of the mobile cloud offloading paradigm and future efforts required. 
Table 3. Offloading process based on MCDA methods.

\begin{tabular}{|c|c|c|c|c|c|c|}
\hline \multicolumn{2}{|r|}{ Works } & \multicolumn{2}{|c|}{ MCDA Methods } & \multicolumn{3}{|c|}{ Criteria Used to Select the Candidate } \\
\hline Papers & Goal of Utilization MCDA Methods & Certainty & Uncertainty & Network Environment & Cloud Environment & Mobile Environment \\
\hline [50] & Select an optimal cloud-path & AHP, TOPSIS & Fuzzy & Bandwidth & $\begin{array}{l}\text { Availability, security, performance, financial } \\
\text { Alternatives: cloud services }\end{array}$ & $\begin{array}{l}\text { Historical data of mobile } \\
\text { user's experiences }\end{array}$ \\
\hline [51,52] & Select Wireless medium & AHP, TOPSIS & - & $\begin{array}{l}\text { Energy cost of the channel, the link speed } \\
\text { of the channel, the availability of the } \\
\text { interface, monetary cost, the congestion } \\
\text { level of the channel (RTT), and the link } \\
\text { quality of the channel } \\
\text { Alternatives: Bluetooth, WiFi, and 3G }\end{array}$ & - & Context of mobile devices \\
\hline [53] & $\begin{array}{l}\text { Select the candidate that saves energy } \\
\text { consumption and increases the service } \\
\text { availability for user. Select handoff. }\end{array}$ & TOPSIS & Fuzzy & $\begin{array}{l}\text { Energy consumption, connection time } \\
\text { Alternatives: WiFi, Bluetooth, mobile } \\
\text { data networks such as } \\
\text { GPRS/EDGE/3G/4G differs. }\end{array}$ & $\begin{array}{l}\text { Processing energy, Waiting time, } \\
\text { Communication, energy connection time } \\
\text { (estimated time that client would be } \\
\text { connected with the resource } \\
\text { providing service) } \\
\text { Alternatives: Cloud, Cloudlet }\end{array}$ & $\begin{array}{l}\text { Processing energy, waiting time, } \\
\text { communication, energy connection time } \\
\text { (estimated time that client would be } \\
\text { connected with the resource } \\
\text { providing service) } \\
\text { Alternatives: peer mobile device }\end{array}$ \\
\hline [54] & Find the lowest execution cost & binary decision & - & - & $\begin{array}{l}\text { Execution time, consumed energy. } \\
\text { Alternatives: remote execution }\end{array}$ & $\begin{array}{l}\text { Execution time, consumed energy } \\
\text { Alternatives: local execution }\end{array}$ \\
\hline [55] & $\begin{array}{l}\text { Optimize the execution time of } \\
\text { offloaded components in the cloud and } \\
\text { minimize the remote execution cost } \\
\text { and energy consumption. }\end{array}$ & Multi-Objective & - & Data transfer size & $\begin{array}{l}\text { Execution Cost, hops, dependency across } \\
\text { non-collocated components, degree of } \\
\text { parallelism, data transfer and } \\
\text { configuration time } \\
\text { Alternatives: cloud servers }\end{array}$ & - \\
\hline [56] & $\begin{array}{l}\text { Select an ideal cloud from for } \\
\text { offloading application }\end{array}$ & AHP & Fuzzy & - & $\begin{array}{l}\text { Availability, capacity, privacy, speed, cost } \\
\text { Alternatives: clouds }\end{array}$ & - \\
\hline$[57]$ & $\begin{array}{l}\text { Allocate resource of neighboring } \\
\text { mobile devices by determining the best } \\
\text { compromise solution without the need } \\
\text { of user preferences }\end{array}$ & TOPSIS & - & - & - & $\begin{array}{l}\text { Completion time, energy } \\
\text { Alternatives: NSGA-II Pareto solutions } \\
\text { of neighboring mobile devices }\end{array}$ \\
\hline$[58]$ & $\begin{array}{l}\text { Take decision to offload from LTE-A to } \\
\text { Wi-Fi based on based on QoE }\end{array}$ & - & Fuzzy logic & $\begin{array}{l}\text { Average Revenue Per User (ARPU), End } \\
\text { to End Delay (E2E Delay), Packet Loss } \\
\text { Ratio (PLR), Received Signal Strength } \\
\text { Indication (RSSI), Throughput SLA } \\
\text { (Service Level Agreement) } \\
\text { Alternatives: LTE-A and Wi-Fi }\end{array}$ & - & QoE perceived by mobile user \\
\hline [59] & Determine the offloading ratio. & - & Fuzzy & $\begin{array}{l}\text { link delay, signal to noise ratio (SNR) } \\
\text { Alternatives: Wi-Fi, cellular }\end{array}$ & - & Alternatives: User SNR \\
\hline$[60]$ & $\begin{array}{l}\text { Redirect transparently and dynamically } \\
\text { users' requests from host cloudlet to } \\
\text { other cloudlets according to the latest } \\
\text { network and server status. }\end{array}$ & - & Neuro-Fuzzy & - & $\begin{array}{l}\text { Round-trip time (RTT) between cloudlets, } \\
\text { Status of cloudlet servers. } \\
\text { Alternatives: Cloudlets }\end{array}$ & - \\
\hline
\end{tabular}


Table 3. Cont

\begin{tabular}{|c|c|c|c|c|c|}
\hline & Works & MCDA Methods & & Criteria Used to Select the Candidate & \\
\hline [61] & $\begin{array}{l}\text { Enhance the code offloading decision } \\
\text { process of a mobile device by applying } \\
\text { machine learning to optimize the } \\
\text { prediction of the final solution, and } \\
\text { quantifying how the execution of a } \\
\text { mobile component could be segregated } \\
\text { to local or remote processing. }\end{array}$ & Fuzzy sets & $\begin{array}{l}\text { low speed, normal speed and high speed } \\
\text { Alternatives: Bandwidth }\end{array}$ & $\begin{array}{l}\text { Historical data } \\
\text { Alternatives: cloud }\end{array}$ & $\begin{array}{l}\text { Low, medium, normal, high } \\
\text { Alternatives: video, data, CPU }\end{array}$ \\
\hline [62] & $\begin{array}{l}\text { Analyze the decision process of } \\
\text { whether to offload or not a mobile } \\
\text { partition in the cloud. Select one } \\
\text { candidate of the multiple available } \\
\text { offloading servers. }\end{array}$ & $\begin{array}{c}\text { Markov } \\
\text { Decision process }\end{array}$ & $\begin{array}{l}\text { Available bandwidth at the offloading } \\
\text { server }\end{array}$ & $\begin{array}{l}\text { CPU load, Available data rate, Round Trip } \\
\text { Time (RTT), Execution time, power cost } \\
\text { Alternatives: offloading servers }\end{array}$ & $\begin{array}{l}\text { Execution time, battery power cost } \\
\text { Alternatives: Partition }\end{array}$ \\
\hline
\end{tabular}




\subsection{Certainty in MCC}

Recent literature has focused on using decision algorithms to specify the most appropriate solution for offloading and fill the gap between the existing technologies in MCC such as the work presented in [50], which has proposed an optimal cloud-path selection method in mobile cloud offloading systems based on QoS criteria. The study addresses the new challenges of cloud service selection that are raised when combing cloud computing with the mobile environment. Accordingly, the authors have combined the Analytic Hierarchy Process (AHP) and fuzzy TOPSIS to make a decision to select a service from the candidate cloud services by considering the characteristics of the mobile cloud environment such as network bandwidth and the historical data based on mobile user experiences. Similarly, AHP and TOPSIS methods have been used in [52] to select a wireless medium based on the different context of the mobile devices. Moreover, this work has adopted a Min-Min heuristic to select an appropriate cloud platform among multiple types of mobile cloud resources (i.e., cloud, cloudlet, and mobile ad-hoc cloud) for offloading. As a result, the proposed solution has addressed the heterogeneity in the mobile cloud environment to enhance the offloading service availability and performance.

Among the selected works, we found that the AHP is the most proposed approach in the literature [31] since it is one of the famous fundamental approaches in MCDA [21]. The main principle of AHP is descripted as follows: A numerical weight is calculated for each alternative of the hierarchy. Then, the AHP method determines the relative importance of a set of alternatives and ranks them into a hierarchy. Finally, it provides the recommended decision with an opportunity to select the suitable service based on the criteria. To obtain the most efficient results, the AHP method is combined with diverse methods, i.e., TOPSIS [21,33], which is a well-known multi-criteria decision-making ranking method. The main features of TOPSIS are chosen as the alternatives that simultaneously have the shortest distance from the ideal solution and the farthest distance from the anti-ideal solution. On this basis, many decision making methods use or extend TOPSIS in order to determine the ideal solution such as $[52,53,57]$. Based on our survey, we found that the utilization of MCDA methods depends on the particular use at a particular step of the offloading process leading to considering a problem in part of the mobile cloud environment, such as [51], which focuses on the selection of an optimal wireless medium. This means that MCDA methods are used to ascertain whether, when, where, or how migration should take place. Yet, the MCDA methods should be integrated in all stages of the offloading process to enhance the reliability of this operation as well as support such dynamics in the mobile cloud environment.

\subsection{Uncertainty and Fuzzy Method}

We notice that the fuzzy method is prevalently used in mobile cloud offloading since this method is characterized by using linguistic variables to describe fuzzy terms that are then mapped to numerical variables [63-65]. Moreover, it deals effectively with uncertain and imprecise information to solve real-world problems in different domains such as bioenergy production technologies [66], cloud storage service [67], e-learning [68], microgrids [69,70], and so on. However, the selected works do not describe how the fuzzy method is used to face and understand the stochastic behavior of the mobile cloud offloading process. On the other hand, there are different extensions of the fuzzy method that can fit particular decision problems and provide good results, such as type-2 fuzzy sets [71,72], intuitionistic fuzzy sets $[73,74]$, fuzzy multisets $[75,76]$, nonstationary fuzzy sets $[77,78]$, and hesitant fuzzy sets [79-81], etc. Meanwhile, there are several uncertainty methods that have been employed for complex problems, such as set pair analysis (SPA) [82], which considers both certainty and uncertainty as one system. Besides, the consolidate certain-uncertain system is depicted from three aspects which are: identity, discrepancy, and contrary. Consequently, SPA has been successfully applied in many fields including smart cities' innovation ecosystem [83,84], forecasting [85], geology [86], and cloud computing [24], etc. However, they are not yet used in the mobile cloud offloading process. This means that the utilization of MCDA methods is still in an early stage in the mobile cloud environment. 
As a result, we need more deep studies in MCC, notably for the offloading process, that focus on exploiting these methods to open new opportunities and further enhance the capabilities of mobile cloud applications.

\subsection{Diversity in $M C C$}

As seen in Table 3, different criteria are selected from various environments in MCC, which are cloud platforms, networks, and mobile environments. Due to this diversity, if one of these environments fails to continue the offloading (or delegation) process, the effectiveness of MCC deployment may be greatly degraded. On the other hand, each environment of the MCC paradigm contains various sub-technologies that are complex [25] (Figure 3). For example, the 5th generation mobile network (5G), which is expected to be operational by 2020, is provisioned to support various types of emerging applications with strengthened quality of service [87-90]. Besides, it will provide a common core to support different coexisting radio access technologies [91]. Therefore, the 5G will use the existing radio access to carry higher data traffic. Moreover, by using a bandwidth of unlimited access, the coming $5 \mathrm{G}$ technology will respond to the extremely diverse applications' requirements in terms of capacity, latency, data rate, and energy cost. Briefly, the 5G will be able to share data everywhere, every time, by everyone and everything, for the benefits of several domains [92-96] such as healthcare and business, as well as computation offloading in MCC. Further, the 5G will guarantee the users' satisfaction by providing service based on users' preferences [97]. However, in the case of MCC, it is difficult to find a standard link between heterogeneous wireless networks, multiple cloud services [98], and preferences of mobile clients. Consequently, the shift from service orientation to user orientation in requirements and innovations is a big deal for 5G, especially in MCC, because the determination of the relationship between quality of services, quality of users' experiences, parameters characterizing traffic sources, and cloud services will link to complex multi-service networks, multi-cloud platforms, and the utility gain of customers' satisfaction.

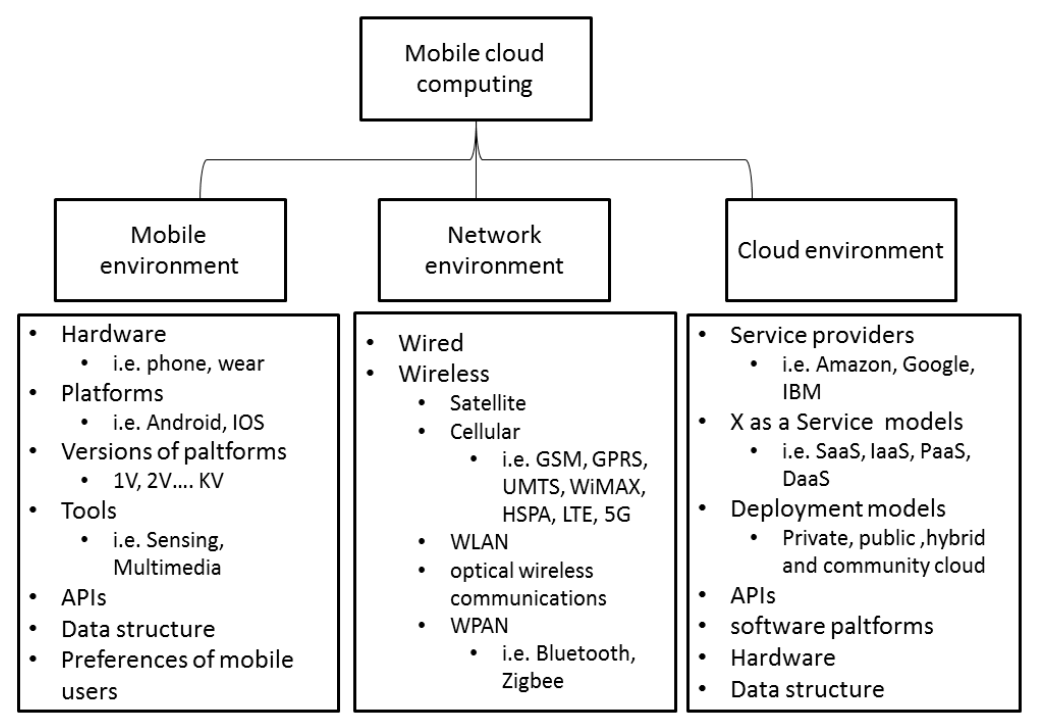

Figure 3. Diversity in the mobile cloud environment.

\subsection{Performance Criteria}

Among the selected papers, we found that energy, cost, execution time, transmission of data, delay, and availability of cloud services (or servers) are investigated as criteria in MCDA methods to ensure the performance of the selected services for mobile applications. With the rapid growth of multiple services in MCC, the mobile users wish to consume reliable services in MCC with low cost and energy consumption. Moreover, the mobile clients demand the guarantee of the execution 
of mobile applications in real time without any delay or network interruption. On the other hand, we found that a number of cloud services have been offered with similar functionalities and different QoSs. This proliferation makes it difficult for mobile cloud customers to find a proper service among a large number of available service candidates. Thus, we observe that the quality of experience (QoE) is used as a strong criterion to satisfy users' requirements, since it is considered as a previous measure of the degree of the end-user's satisfaction which results from his real experience after using a service. Thus, the cloud providers use QoE as an important parameter to enhance the selection of cloud services as well as minimize (or avoid) the failure of the SLA.

In fact, a great number of research works have concentrated on selecting cloud services in which the important decision-making basis is a direct experience provided by the consumers. For example, the authors in [50] have highlighted the dynamic nature of the cloud environment and taken into account the multitude of available cloud services. Moreover, they have proposed a novel cloud service selection framework (based on fuzzy, AHP, and TOPSIS methods) in which the mobile user's experiences have been considered to rank all cloud services and determine which one could satisfy the user requirements. Furthermore, the mobile user's experiences are exploited mainly to solve the difficult problem of obtaining the QoS values of criteria and sub-criteria in real systems. Yet, in the case of mobile clients without previous experience, MCDA methods (especially those focusing on studying uncertain and imprecise information in real systems) can hardly solve the studied problem. Big data technologies, particularly data meaning and machine learning, are required to extract the certain and uncertain criteria from the three environments without the need to use the experiences of mobile clients. Consequently, there is a remarkable request for the fusion of MCDA techniques and big data tools to support uncertain and certain information in MCC, as well as to ensure the quality of mobile cloud applications.

\subsection{Cloud Service Recommendation}

The satisfaction of mobile cloud clients has driven the researchers in MCC to introduce new solutions to bring the cloud services and resources closer to them [47]. The proposed solutions are not replacing but complementing the cloud computing model and respecting the primary objective of the mobile cloud computing environment which tackle the limitations of mobile devices. One of these resources is cloudlet $[99,100]$, which is deployed in public places. This type of micro-cloud is a close source of customized cloud assets aiming to reduce communication delay. Also, the mobility concept is exploited in the cloud environment to produce another form of cloudlet nodes known as mobile cloudlets [101-103]. These mobile cloudlets exploit mobile devices (like smartphones) to speed up the accessibility of customized cloud services and increase the execution time by using either Wi-Fi or Bluetooth network interfaces. However, during the process of offloading, the users and/or cloud servers, like mobile cloudlets, may change their locations and become disconnected from each other which may result in the inaccessibility and instability of cloud services. Further, in the case of network disruption, the mobile clients may lose the remote computational results. Another case, when a cloud server handles multiple offloading requests, the CPU utilization may be too high for processing other tasks. Besides, the selected server, i.e., the cloudlet, can only respond to a limited number of requests at a specific moment. Yet, it is better to recommend a cloud server that can ascertain the offloading process.

In fact, the selected works focus on the recommendation (or selection) of services from different cloud platforms in MCC that are affected by user preferences [104], the current context of mobile devices [105-107], and social networks [7,108,109]. That means that there are multiple sources of information that are used to understand the real users' needs, and at the same time, they make the recommendation effectiveness relative, since the nature of these data is unstable and relative. For example, a recommended cloud service via a social network [110-112] could satisfy customers, because it represents the user's opinion and behavior. However, not all the clients will reach the same level of satisfaction or all the time the selected service is adequate and certain adaptively. Yet, what are 
the best MCDA techniques that cloud providers could use to manage the personal social information in the mobile cloud? How can the MCDA methods be used to identify and extract the most relevant personal social information that can be used as criteria to determine and recommend the most efficient public services for the end-users? Therefore, more deep studies in MCDA methods are required to enhance the mobile cloud paradigm, which is rapidly changing and growing in terms of techniques and applications. Moreover, MCDA methods will offer a wide range of promising enhancements and innovations that will dramatically change the recommendation and selection of mobile cloud services in the forthcoming years.

\subsection{Mobility}

To overcome the constraints of mobile applications, different cloud platforms in Figure 4 are used to complement and enhance the capacities of mobile devices. Consequently, offloading intense mobile tasks could be transferred to the cloud data center, cloudlet, mobile cloudlet, or mobile device cloud platform [47]. Then, one of them processes the offloaded information and returns the result to the end-mobile-application. To ascertain the offloading operation, the MCDA methods have to select, compare, and rank different attributes of multiple alternatives in order to determine an optimal and certain cloud platform to handle local mobile resources. However, in the case where the mobile cloudlet uses its own energy and limited computing resources to provide the services, the unstable connections between mobile cloudlet nodes, such as smartphones, tablets, and trams mounted computers, are important issues to achieve an optimal performance of the mobile cloudlet. Maybe cloudlets could provide directly customized cloud services to the nearest users. However, the mobile cloudlet [113] could move between different places and deliver the services to other clients within a given proximity. Therefore, the mobile cloudlet can efficiency minimize the application response time, energy consumption, cost of network resource usage, and latency. Yet, based on our review, we identified the following research questions associated with the selection of an adequate cloud platform, which relate to the stochastic behavior of the mobile client that could act as a provider of services: RQ1 What are the most important factors in mobile cloud offloading that need to be taken into consideration when applying MCDA methods for the scalable selection of services?; RQ2 How could MCDA methods supply the highest mobility of users, and ensure the scalability of selected services?

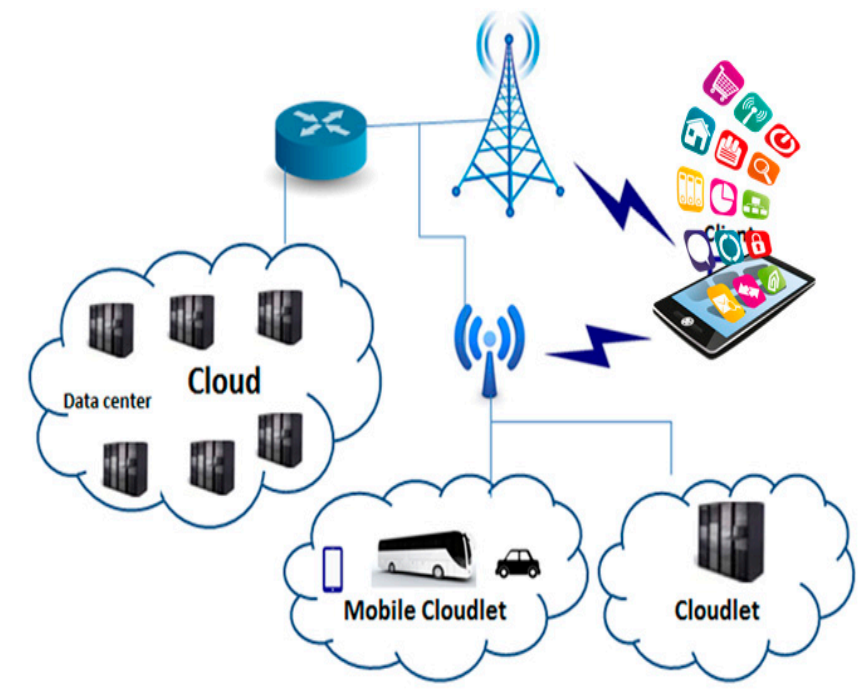

Figure 4. Different cloud platforms.

\section{Conclusions}

In this paper, we have conducted a survey on mobile cloud offloading based on MCDA methods. We have described the concept of the cloud offloading operation and MCDA methods. We have 
identified that the offloading process is strongly relying on the mobile environment, network operators, and cloud services. Thus, we have focused on studying the three typical environments of MCC to clarify how MCDA methods are applied in the mobile cloud offloading paradigm. Notably, we have extracted, summarized, and organized the keywords from the reviewed papers to identify how the elements of MCDA methods are selected from the mobile cloud environment before solving an MCDA problem. Based on our analysis, we have recommended a set of future research directions of MCDA used for the mobile cloud offloading process.

We believe that MCDA methods will enhance the growth of the mobile cloud paradigm in terms of infrastructure and communication. As future work, we plan to investigate how to use MCDA methods in the offloading process, as well as mobile cloud computing in general. Moreover, we would like to investigate Big Data technologies to make the MCDA methods more reliable and effective, as well as to minimize the influence of stochastic factors that affect the sustainability and efficiency of the selected MCDA solutions.

Acknowledgments: The work was supported from European Regional Development Fund-Project "CERIT Scientific Cloud" (No. CZ.02.1.01/0.0/0.0/16_013/0001802).

Author Contributions: The authors contributed equally to this review.

Conflicts of Interest: The authors declare no conflict of interest.

\section{References}

1. Sun, Y.; Song, H.; Jara, A.J.; Bie, R. Internet of things and big data analytics for smart and connected communities. IEEE Access 2016, 4, 766-773. [CrossRef]

2. Dinh, H.T.; Lee, C.; Niyato, D.; Wang, P. A survey of mobile cloud computing: Architecture, applications, and approaches. Wirel. Commun. Mob. Comput. 2013, 13, 1587-1611. [CrossRef]

3. Fernando, N.; Loke, S.W.; Rahayu, W. Mobile cloud computing: A survey. Future Gener. Comput. Syst. 2013, 29, 84-106. [CrossRef]

4. Wang, Y.; Chen, R.; Wang, D. A survey of mobile cloud computing applications: Perspectives and challenges. Wirel. Pers. Commun. 2015, 80, 1607-1623. [CrossRef]

5. Rittinghouse, J.W.; Ransome, J.F. Cloud Computing: Implementation, Management, and Security; CRC Press: Hoboken, NJ, USA, 2016.

6. Bangui, H.; Rakrak, S.; Raghay, S. External sources for mobile computing: The state-of-the-art, challenges, and future research. In Proceedings of the 2015 International Conference on Cloud Technologies and Applications (CloudTech), Marrakech, Morocco, 2-4 June 2015; pp. 1-8.

7. Rahimi, M.R.; Ren, J.; Liu, C.H.; Vasilakos, A.V.; Venkatasubramanian, N. Mobile cloud computing: A survey, state of art and future directions. Mob. Netw. Appl. 2014, 19, 133-143. [CrossRef]

8. Abolfazli, S.; Sanaei, Z.; Sanaei, M.H.; Shojafar, M.; Gani, A. Mobile cloud computing: The-state-of-the-art, challenges, and future research. In Encyclopedia of Cloud Computing; Murugesan, S., Bojanova, I., Eds.; Willeys \& Sons: Hoboken, NJ, USA, 2015.

9. Flores, H.; Hui, P.; Tarkoma, S.; Li, Y.; Srirama, S.; Buyya, R. Mobile code offloading: From concept to practice and beyond. IEEE Commun. Mag. 2015, 53, 80-88. [CrossRef]

10. $\mathrm{Wu}, \mathrm{H}$. Analysis of Offloading Decision Making in Mobile Cloud Computing. Ph.D. Thesis, Freie Universität Berlin, Berlin, Germany, 2015.

11. Islam, M.M.; Razzaque, M.A.; Hassan, M.M.; Nagy, W.; Song, B. Mobile Cloud-Based Big Healthcare Data Processing in Smart Cities. IEEE Access 2017, 5, 11887-11899. [CrossRef]

12. Wu, H.; Wang, Q.; Wolter, K. Mobile healthcare systems with multi-cloud offloading. In Proceedings of the 2013 IEEE 14th International Conference on Mobile Data Management (MDM), Milan, Italy, 3-6 June 2013; Volume 2, pp. 188-193.

13. De Oliveira, A.L.; Moore, Z. Treatment of the diabetic foot by offloading: A systematic review. J. Wound Care 2015, 24, 560-570. [CrossRef] [PubMed] 
14. Kumari, R. An efficient data offloading to cloud mechanism for smart healthcare sensors. In Proceedings of the 2015 1st International Conference on Next Generation Computing Technologies (NGCT), Dehradun, India, 4-5 September 2015; pp. 90-95.

15. Jo, M.; Maksymyuk, T.; Strykhalyuk, B.; Cho, C. Device-to-device-based heterogeneous radio access network architecture for mobile cloud computing. IEEE Wirel. Commun. 2015, 22, 50-58. [CrossRef]

16. Wu, H.; Wolter, K. Stochastic Analysis of Delayed Mobile Offloading in Heterogeneous Networks. IEEE Trans. Mob. Comput. 2017. [CrossRef]

17. Tseng, F.; Cho, H.; Chang, K.; Li, J.; Shih, T.K. Application-oriented offloading in heterogeneous networks for mobile cloud computing. Enterp. Inf. Syst. 2017, 1-16. [CrossRef]

18. Shojafar, M.; Cordeschi, N.; Abawajy, J.H.; Baccarelli, E. Adaptive energy-efficient qos-aware scheduling algorithm for tcp/ip mobile cloud. In Proceedings of the 2015 IEEE Globecom Workshops (GC Wkshps), San Diego, CA, USA, 6-10 December 2015; pp. 1-6.

19. Shojafar, M.; Cordeschi, N.; Baccarelli, E. Energy-efficient adaptive resource management for real-time vehicular cloud services. IEEE Trans. Cloud Comput. 2016. [CrossRef]

20. Ragona, C.; Granelli, F.; Fiandrino, C.; Kliazovich, D.; Bouvry, P. Energy-efficient computation offloading for wearable devices and smartphones in mobile cloud computing. In Proceedings of the 2015 IEEE Global Communications Conference (GLOBECOM), San Diego, CA, USA, 6-10 December 2015; pp. 1-6.

21. Whaiduzzaman, M.; Gani, A.; Anuar, N.B.; Shiraz, M.; Haque, M.N.; Haque, I.T. Cloud service selection using multicriteria decision analysis. Sci. World J. 2014. [CrossRef] [PubMed]

22. Kabir, G.; Sadiq, R.; Tesfamariam, S. A review of multi-criteria decision-making methods for infrastructure management. Struct. Infrastruct. Eng. 2014, 10, 1176-1210. [CrossRef]

23. Mustajoki, J.; Marttunen, M. Comparison of multi-criteria decision analytical software for supporting environmental planning processes. Environ. Model. Softw. 2017, 93, 78-91. [CrossRef]

24. Li, L.; Hang, J.; Gao, Y.; Mu, C. Using an Integrated Group Decision Method Based on SVM, TFN-RS-AHP, and TOPSIS-CD for Cloud Service Supplier Selection. Math. Probl. Eng. 2017. [CrossRef]

25. Sanaei, Z.; Abolfazli, S.; Gani, A.; Buyya, R. Heterogeneity in mobile cloud computing: Taxonomy and open challenges. IEEE Commun. Surv. Tutor. 2014, 16, 369-392. [CrossRef]

26. Dyer, J. Multiple criteria decision analysis: State of the art surveys. Int. Ser. Oper. Res. Manag. Sci. 2005, 78, 265-292.

27. Durbach, I.N.; Stewart, T.J. Modeling uncertainty in multi-criteria decision analysis. Eur. J. Oper. Res. 2012, 223, 1-14. [CrossRef]

28. Van Til, J.; Groothuis-Oudshoorn, C.; Lieferink, M.; Dolan, J.; Goetghebeur, M. Does technique matter; a pilot study exploring weighting techniques for a multi-criteria decision support framework. Cost Eff. Resour. Alloc. 2014, 12, 22. [CrossRef] [PubMed]

29. Zyoud, S.H.; Fuchs-Hanusch, D. A bibliometric-based survey on AHP and TOPSIS techniques. Expert Syst. Appl. 2017. [CrossRef]

30. Cid-López, A.; Hornos, M.J.; Carrasco, R.A.; Herrera-Viedma, E. Applying a linguistic multi-criteria decision-making model to the analysis of ICT suppliers' offers. Expert Syst. Appl. 2016, 57, 127-138. [CrossRef]

31. Saaty, T.L. Decision making—the analytic hierarchy and network processes (AHP/ANP). J. Syst. Sci. Syst. Eng. 2004, 13, 1-35. [CrossRef]

32. San Cristóbal, J.R. Multi-criteria decision-making in the selection of a renewable energy project in Spain: The Vikor method. Renew. Energy 2011, 36, 498-502. [CrossRef]

33. Hwang, C.; Lai, Y.; Liu, T. A new approach for multiple objective decision making. Comput. Oper. Res. 1993, 20, 889-899. [CrossRef]

34. Wei, G.W. Gray relational analysis method for intuitionistic fuzzy multiple attribute decision making. Expert Syst. Appl. 2011, 38, 11671-11677. [CrossRef]

35. Mohammadshahi, Y. A state-of-art survey on TQM applications using MCDM techniques. Decis. Sci. Lett. 2013, 2, 125-134. [CrossRef]

36. Alabool, H.M.; Mahmood, A.K. Trust-based service selection in public cloud computing using fuzzy modified VIKOR method. Aust. J. Basic Appl. Sci. 2013, 7, 211-220.

37. Keeney, R.L.; Raiffa, H. Decision with Multiple Objectives; Cambridge University Press: Cambridge, UK, 1976. 
38. Dyer, J.S. MAUT-Multiattribute Utility Theory. In Multiple Criteria Decision Analysis: State of the Art Surveys; Springer: New York, NY, USA, 2005; pp. 265-292.

39. Dağdeviren, M.; Yavuz, S.; Kılınç, N. Weapon selection using the AHP and TOPSIS methods under fuzzy environment. Expert Syst. Appl. 2009, 36, 8143-8151. [CrossRef]

40. Sarlak, M.A.; Keshavarz, E.; Keshavarz, A. Evaluation and survey of knowledge management tools using fuzzy AHP and fuzzy TOPSIS techniques. Int. J. Bus. Innov. Res. 2017, 13, 363-387. [CrossRef]

41. Asgary, A.; Asgary, A.; Pantin, B.; Pantin, B.; Saiiar, B.E.; Saiiar, B.E.; Wu, J.; Wu, J. Developing disaster mutual assistance decision criteria for electricity industry. Disaster Prev. Manag. Int. J. 2017, 26, 230-240. [CrossRef]

42. Sadi-Nezhad, S. A state-of-art survey on project selection using MCDM techniques. J. Proj. Manag. 2017, 2, 1-10. [CrossRef]

43. Behzadian, M.S. Khanmohammadi Otaghsara, Morteza Yazdani, and Joshua Ignatius. A state-of the-art survey of TOPSIS applications. Expert Syst. Appl. 2012, 39, 13051-13069. [CrossRef]

44. Nunes, L.H.; Estrella, J.C.; Delbem, A.N.; Perera, C.; Reiff-Marganiec, S. The effects of relative importance of user constraints in cloud of things resource discovery: A case study. In Proceedings of the 9th International Conference on Utility and Cloud Computing, Shanghai, China, 6-9 December 2016; pp. 245-250.

45. Web of Science Platform. Available online: https://webofknowledge.com (accessed on 29 October 2017).

46. Zhang, W.; Tan, S.; Xia, F.; Chen, X.; Li, Z.; Lu, Q.; Yang, S. A survey on decision making for task migration in mobile cloud environments. Pers. Ubiquitous Comput. 2016, 20, 295-309. [CrossRef]

47. Bangui, H.; Buhnova, B.; Rakrak, S.; Raghay, S. Smart mobile technologies for the city of the future. In Proceedings of the Smart City Symposium Prague (SCSP), Prague, Czech Republic, 25-26 May 2017; pp. 1-6.

48. Flores, H.; Srirama, S.N.; Buyya, R. Computational offloading or data binding? bridging the cloud infrastructure to the proximity of the mobile user. In Proceedings of the 2014 2nd IEEE International Conference on Mobile Cloud Computing, Services, and Engineering (MobileCloud), Oxford, UK, 7-10 April 2014; pp. 10-18.

49. Bangui, H.; Rakrak, S. Mobile Cloud Middleware: Smart Behaviour for Adapting Cloud Services. In Proceedings of the 2014 Tenth International Conference on Signal-Image Technology and Internet-Based Systems (SITIS), Marrakech, Morocco, 23-27 November 2014; pp. 682-686.

50. Wu, H.; Wang, Q.; Wolter, K. Optimal cloud-path selection in mobile cloud offloading systems based on QoS criteria. Int. J. Grid High Perform. Comput. 2013, 5, 30-47. [CrossRef]

51. Zhou, B.; Dastjerdi, A.V.; Calheiros, R.N.; Srirama, S.N.; Buyya, R. A context sensitive offloading scheme for mobile cloud computing service. In Proceedings of the 2015 IEEE 8th International Conference on Cloud Computing (CLOUD), New York, NY, USA, 27 June-2 July 2015; pp. 869-876.

52. Zhou, B.; Dastjerdi, A.V.; Calheiros, R.; Srirama, S.; Buyya, R. mCloud: A Context-aware offloading framework for heterogeneous mobile cloud. IEEE Trans. Serv. Comput. 2015, 10, 797-810. [CrossRef]

53. Ravi, A.; Peddoju, S.K. Handoff strategy for improving energy efficiency and cloud service availability for mobile devices. Wirel. Pers. Commun. 2015, 81, 101-132. [CrossRef]

54. Neto, J.L.D.; Yu, S.; Macedo, D.; Nogueira, J.M.S.; Langar, R.; Secci, S. ULOOF: A User Level Online Offloading Framework for Mobile Edge Computing. Hal-01547036, Version 1. Available online: http:/ /hal.upmc.fr/hal01547036/document (accessed on 29 October 2017).

55. Ahmed, E.; Khan, S.; Yaqoob, I.; Gani, A.; Salim, F. Multi-objective optimization model for seamless application execution in mobile cloud computing. In Proceedings of the 2013 5th International Conference on Information and Communication Technologies (ICICT), Karachi, Pakistan, 14-15 December 2013; pp. 1-6.

56. Singla, C.; Kaushal, S. Cloud path selection using fuzzy analytic hierarchy process for offloading in mobile cloud computing. In Proceedings of the 2015 2nd International Conference on Recent Advances in Engineering and Computational Sciences (RAECS), Chandigarh, India, 21-22 December 2015; pp. 1-5.

57. Ghasemi-Falavarjani, S.; Nematbakhsh, M.; Ghahfarokhi, B.S. Context-aware multi-objective resource allocation in mobile cloud. Comput. Electr. Eng. 2015, 44, 218-240. [CrossRef]

58. Torjemen, N.; Zhioua, G.; Tabbane, N. QoE model based on fuzzy logic system for offload decision in HetNets environment. In Proceedings of the 2017 International Conference on Information and Digital Technologies (IDT), Zilina, Slovakia, 5-7 July 2017; pp. 482-485. 
59. Hosseini, S.M.; Kazeminia, M.; Mehrjoo, M.; Barakati, S.M. Fuzzy logic based mobile data offloading. In Proceedings of the 2015 23rd Iranian Conference on Electrical Engineering (ICEE), Tehran, Iran, 10-14 May 2015; pp. 397-401.

60. Rashidi, S.; Sharifian, S. Cloudlet dynamic server selection policy for mobile task off-loading in mobile cloud computing using soft computing techniques. J. Supercomput. 2017, 73, 3796-3820. [CrossRef]

61. Flores, H.; Srirama, S. Adaptive code offloading for mobile cloud applications: Exploiting fuzzy sets and evidence-based learning. In Proceedings of the Fourth ACM Workshop on Mobile Cloud Computing and Services, Taipei, Taiwan, 25-28 June 2013; pp. 9-16.

62. Zannat, H.; Hossain, M.S. A hybrid framework using Markov decision process for mobile code offloading. In Proceedings of the 2016 19th International Conference on Computer and Information Technology (ICCIT), Dhaka, Bangladesh, 18-20 December 2016; pp. 31-35.

63. Kahraman, C.; Öztayşi, B.; Onar, S.Ç. A comprehensive literature review of 50 years of fuzzy set theory. Int. J. Comput. Intell. Syst. 2016, 9, 3-24. [CrossRef]

64. Lai, G.; Liu, Z.; Zhang, Y.; Chen, C.L.P.; Xie, S.; Liu, Y. Fuzzy adaptive inverse compensation method to tracking control of uncertain nonlinear systems with generalized actuator dead zone. IEEE Trans. Fuzzy Syst. 2017, 25, 191-204. [CrossRef]

65. Mendel, J.M. Uncertain Rule-Based Fuzzy Logic Systems: Introduction and New Directions; Prentice Hall PTR: Upper Saddle River, NJ, USA, 2001.

66. Khishtandar, S.; Zandieh, M.; Dorri, B. A multi criteria decision making framework for sustainability assessment of bioenergy production technologies with hesitant fuzzy linguistic term sets: The case of Iran. Renew. Sustain. Energy Rev. 2017, 77, 1130-1145. [CrossRef]

67. Esposito, C.; Ficco, M.; Palmieri, F.; Castiglione, A. Smart cloud storage service selection based on fuzzy logic, theory of evidence and game theory. IEEE Trans. Comput. 2016, 65, 2348-2362. [CrossRef]

68. Su, C.H.; Tzeng, G.; Hu, S. Cloud e-learning service strategies for improving e-learning innovation performance in a fuzzy environment by using a new hybrid fuzzy multiple attribute decision-making model. Interact. Learn. Environ. 2016, 24, 1812-1835. [CrossRef]

69. Parhoudeh, S.; Baziar, A.; Mazareie, A.; Kavousi-Fard, A. A novel stochastic framework based on fuzzy cloud theory for modeling uncertainty in the micro-grids. Int. J. Electr. Power Energy Syst. 2016, 80, 73-80. [CrossRef]

70. Zare, J.; Zare, A. An intelligent stochastic method based on fuzzy cloud theory for modeling uncertainty effects in the renewable micro-grids. J. Intell. Fuzzy Syst. 2016, 30, 3727. [CrossRef]

71. Mendel, J.M. Type-2 fuzzy Sets. In Uncertain Rule-Based Fuzzy Systems; Springer: Cham, Switzerlands, 2017; pp. 259-306.

72. Mendel, J.M.; John, R.I.B. Type-2 fuzzy sets made simple. IEEE Trans. Fuzzy Syst. 2002, 10, 117-127. [CrossRef]

73. Garg, H. A new generalized improved score function of interval-valued intuitionistic fuzzy sets and applications in expert systems. Appl. Soft Comput. 2016, 38, 988-999. [CrossRef]

74. Atanassov, K.T. Intuitionistic fuzzy sets. Fuzzy Sets Syst. 1986, 20, 87-96. [CrossRef]

75. Paul, J.; John, S.J. On Some Algebraic Structures of Type 2 Fuzzy Multisets. Int. J. Fuzzy Syst. Appl. (IJFSA) 2017, 6, 1-24. [CrossRef]

76. Tripathy, B.K. On theory of multisets and applications. In Handbook of Research on Generalized and Hybrid Set Structures and Applications for Soft Computing; IGI Global: Hershey, PA, USA, 2016; pp. 1-22.

77. Yetis, H.; Karakose, M. Nonstationary Fuzzy Systems for Modelling and Control in Cyber Physical Systems under Uncertainty. Int. J. Intell. Syst. Appl. Eng. 2017, 26-30. [CrossRef]

78. Garibaldi, J.M.; Jaroszewski, M.; Musikasuwan, S. Nonstationary fuzzy sets. IEEE Trans. Fuzzy Syst. 2008, 16, 1072-1086. [CrossRef]

79. Alcantud, J.C.R.; Torra, V. Decomposition theorems and extension principles for hesitant fuzzy sets. Inf. Fusion 2018, 41, 48-56. [CrossRef]

80. Aliahmadipour, L.; Torra, V.; Eslami, E. On hesitant fuzzy clustering and clustering of hesitant fuzzy data. In Fuzzy Sets, Rough Sets, Multisets and Clustering; Springer: Cham, Switzerlands, 2017; pp. 157-168.

81. Wei, C.; Rodríguez, R.M.; Martínez, L. Uncertainty Measures of Extended Hesitant Fuzzy Linguistic Term Sets. IEEE Trans. Fuzzy Syst. 2017. [CrossRef]

82. Aili, Z.K.X. Set Pair Theory-A New Theory Method of Non-Define and Its Applications. Syst. Eng. 1996, 1, 3. 
83. Su, M.; Li, R.; Lu, W.; Chen, C.; Chen, B.; Yang, Z. Evaluation of a low-carbon city: Method and application. Entropy 2013, 15, 1171-1185. [CrossRef]

84. Tan, S.; Yang, J.; Yan, J.; Lee, C.; Hashim, H.; Chen, B. A holistic low carbon city indicator framework for sustainable development. Appl. Energy 2017, 185, 1919-1930. [CrossRef]

85. Zou, Q.; Zhou, J.; Zhou, C.; Song, L.; Guo, J. Comprehensive flood risk assessment based on set pair analysis-variable fuzzy sets model and fuzzy AHP. Stoch. Environ. Res. Risk Assess. 2013, 27, 525-546. [CrossRef]

86. Wang, Y.; Jing, H.; Yu, L.; Su, H.; Luo, N. Set pair analysis for risk assessment of water inrush in karst tunnels. Bull. Eng. Geol. Environ. 2017, 76, 1199-1207. [CrossRef]

87. Andrews, J.G.; Buzzi, S.; Choi, W.; Hanly, S.V.; Lozano, A.; Soong, A.C.K.; Zhang, J.C. What will 5G be? IEEE J. Sel. Areas Commun. 2014, 32, 1065-1082. [CrossRef]

88. Wang, C.-X.; Haider, F.; Gao, X.; You, X.; Yang, Y.; Yuan, D.; Aggoune, H.; Haas, H.; Fletcher, S.; Hepsaydir, E. Cellular architecture and key technologies for $5 \mathrm{G}$ wireless communication networks. IEEE Commun. Mag. 2014, 52, 122-130. [CrossRef]

89. Agiwal, M.; Roy, A.; Saxena, N. Next generation 5G wireless networks: A comprehensive survey. IEEE Commun. Surv. Tutor. 2016, 18, 1617-1655. [CrossRef]

90. Gupta, A.; Jha, R.K. A survey of 5G network: Architecture and emerging technologies. IEEE Access 2015, 3, 1206-1232. [CrossRef]

91. Dahlman, E.; Parkvall, S.; Skold, J. 4G, LTE-advanced Pro and the Road to 5G; Academic Press: London, UK, 2016.

92. Vannithamby, R.; Talwar, S. (Eds.) Towards 5G: Applications, Requirements and Candidate Technologies; John Wiley and Sons: Hoboken, NJ, USA, 2017.

93. Chen, M.; Yang, J.; Hao, Y.; Mao, S.; Hwang, K. A 5G cognitive system for healthcare. Big Data Cognit. Comput. 2017, 1, 2. [CrossRef]

94. Din, S.; Paul, A.; Ahmad, A.; Rho, S. Emerging Mobile Communication Technologies for Healthcare System in 5G Network. In Proceedings of the 14th International Conference on Dependable, Autonomic and Secure Computing, 14th International Conference on Pervasive Intelligence and Computing, 2nd International Conference on Big Data Intelligence and Computing and Cyber Science and Technology Congress (DASC/PiCom/DataCom/CyberSciTech), Auckland, New Zealand, 8-12 August 2016; pp. 47-54.

95. Ho, J.; Zhang, J.; Jo, M. Selective offloading to WiFi devices for 5G mobile users. In Proceedings of the 2017 13th International Conference on Wireless Communications and Mobile Computing Conference (IWCMC), Valencia, Spain, 26-30 June 2017; pp. 1047-1054.

96. Ahokangas, P.; Moqaddamerad, S.; Matinmikko, M.; Abouzeid, A.; Atkova, I.; Gomes, J.F.; Iivari, M. Future micro operators business models in 5G. Bus. Manag. Rev. 2016, 7, 143.

97. Nieto, A.; Nomikos, N.; Lopez, J.; Skianis, C. Dynamic Knowledge-Based Analysis in Nonsecure 5G Green Environments Using Contextual Data. IEEE Syst. J. 2015. [CrossRef]

98. Carvalho, G.H.S.; Woungang, I.; Anpalagan, A.; Jaseemuddin, M.; Hossain, E. Intercloud and HetNet for Mobile Cloud Computing in 5G Systems: Design Issues, Challenges, and Optimization. IEEE Netw. 2017, 31, 80-89. [CrossRef]

99. Sun, X.; Ansari, N. Green cloudlet network: A distributed green mobile cloud network. IEEE Netw. 2017, 31, 64-70. [CrossRef]

100. Shaukat, U.; Ahmed, E.; Anwar, Z.; Xia, F. Cloudlet deployment in local wireless networks: Motivation, architectures, applications, and open challenges. J. Netw. Comput. Appl. 2016, 62, 18-40. [CrossRef]

101. Abolfazli, S.; Sanaei, Z.; Gani, A.; Xia, F.; Lin, W. Rmcc: Restful mobile cloud computing framework for exploiting adjacent service-based mobile cloudlets. In Proceedings of the 2014 IEEE 6th International Conference on Cloud Computing Technology and Science (CloudCom), Singapore, 15-18 December 2014; pp. 793-798.

102. Jin, H.; Yan, S.; Zhao, C.; Liang, D. PMC ${ }^{2} \mathrm{O}$ : Mobile cloudlet networking and performance analysis based on computation offloading. Ad Hoc Netw. 2017, 58, 86-98. [CrossRef]

103. Fang, W.; Yao, X.; Zhao, X.; Yin, J.; Xiong, N. A Stochastic Control Approach to Maximize Profit on Service Provisioning for Mobile Cloudlet Platforms. IEEE Trans. Syst. Man Cybern. Syst. 2016. [CrossRef]

104. Rehman, Z.; Hussain, O.K.; Hussain, F.K. User-side cloud service management: State-of-the-art and future directions. J. Netw. Comput. Appl. 2015, 55, 108-122. [CrossRef] 
105. Nunna, S.; Ganesan, K. Mobile Edge Computing. In Health 4.0: How Virtualization and Big Data Are Revolutionizing Healthcare; Springer: Cham, Switzerlands, 2017; pp. 187-203.

106. Guerrero-Contreras, G.; Garrido, J.L.; Balderas-Diaz, S.; Rodriguez-Dominguez, C. A context-aware architecture supporting service availability in mobile cloud computing. IEEE Trans. Serv. Comput. 2016. [CrossRef]

107. Martín, D.; Lamsfus, C.; Alzua-Sorzabal, A. A cloud-based platform to develop context-aware mobile applications by domain experts. Comput. Stand. Interfaces 2016, 44, 177-184. [CrossRef]

108. Zhu, C.; Wang, H.; Leung, V.C.M.; Shu, L.; Yang, L.T. An evaluation of user importance when integrating social networks and mobile cloud computing. In Proceedings of the 2014 IEEE Global Communications Conference (GLOBECOM), Austin, TX, USA, 8-12 December 2014; pp. 2935-2940.

109. Zhenyu, W.; Chunhong, Z.; Yang, J.; Hao, W. Towards cloud and terminal collaborative mobile social network service. In Proceedings of the 2010 IEEE Second International Conference on Social Computing (SocialCom), Minneapolis, MN, USA, 20-22 August 2014; pp. 623-629.

110. Tang, L.; Chen, X.; He, S. When Social Network Meets Mobile Cloud: A Social Group Utility Approach for Optimizing Computation Offloading in Cloudlet. IEEE Access 2016, 4, 5868-5879. [CrossRef]

111. Gupta, S.B.; Gupta, B.; Chaudhary, P. Hunting for DOM-Based XSS vulnerabilities in mobile cloud-based online social network. Future Gener. Comput. Syst. 2017. [CrossRef]

112. Li, H.; Liu, D.; Dai, Y.; Luan, T.H. Engineering searchable encryption of mobile cloud networks: When QoE meets QoP. IEEE Wirel. Commun. 2015, 22, 74-80. [CrossRef]

113. Li, Y.; Wang, W. Can mobile cloudlets support mobile applications? In Proceedings of the IEEE Infocom, Toronto, ON, Canada, 27 April-2 May 2014; pp. 1060-1068.

(C) 2017 by the authors. Licensee MDPI, Basel, Switzerland. This article is an open access article distributed under the terms and conditions of the Creative Commons Attribution (CC BY) license (http:// creativecommons.org/licenses/by/4.0/). 